Article

\title{
Terrestrial Laser Scanner for the Formal Assessment of a Roman-Medieval Structure-The Cloister of the Cathedral of Tarragona (Spain)
}

\author{
Felipe Buill ${ }^{1, *}$, M. Amparo Núñez-Andrés ${ }^{1}{ }^{(0)}$, Agustí Costa-Jover ${ }^{2}{ }^{(0)}$, David Moreno ${ }^{2}{ }^{\circledR}$, \\ Josep M. Puche ${ }^{3}$ and Josep M. Macias ${ }^{3}$ (I) \\ 1 Civil and Environmental Department, Division of Geotechnical Engineering and Geosciences, Universitat \\ Politècnica de Catalunya, 08028 Barcelona, Spain; m.amparo.nunez@upc.edu \\ 2 Escola Tècnica Superior d'Arquitectura (ETSA), Universitat Rovira i Virgili, 43204 Tarragona, Spain; \\ agusti.costa@urv.cat (A.C.-J.); david.moreno@urv.cat (D.M.) \\ 3 Institut Català d'Arqueologia Clàssica (ICAC), 43003 Tarragona, Spain; jpuche@icac.cat (J.M.P.); \\ jmmacias@icac.cat (J.M.M.) \\ * Correspondence: felipe.buill@upc.edu; Tel.: +34-934-05-40-19
}

Received: 29 September 2020; Accepted: 26 October 2020; Published: 28 October 2020

\begin{abstract}
The use of massive data capture techniques in architectural heritage has enhanced the development of new methodologies that have an important impact on their conservation and understanding. The research proposes the study of formal anomalies in the cloister of the Cathedral of Tarragona (c. 12th century). It is a relevant Gothic construction in Catalonia, with the special singularity that part of its structure is raised over an important pre-existing Roman wall. The investigation is based on a point cloud obtained with a terrestrial laser scanner (TLS) and the systematization of the 3D analysis methodology of the point cloud through different reference shapes. In general terms, the construction is in good condition, so the discrepancies between real construction and the shapes of reference are small, with some exceptions. Nevertheless, the different approximations used allowed us to identify some relevant features, such as the variability of the form of rib vaults, and the influence of the criteria used in the definition and location of reference forms.
\end{abstract}

Keywords: terrestrial laser scanner; cultural heritage; formal assessment; Tarragona cathedral

\section{Introduction}

Topographic surveying techniques have seen a great technological evolution in recent decades. The appearance of massive data capture techniques has raised countless applications in very diverse disciplines, such as geomorphology [1], volcanology [2], prototyping [3], construction materials [4], and also cultural heritage [5], both architectural and archaeological. In these areas, we find numerous works based on surveys carried out mainly with a terrestrial laser scanner (TLS) [6,7], digital photogrammetry $[8,9]$, or a combination of both $[10,11]$. The reliability and accuracy of these systems has been extensively tested and verified [12-14].

These systems offer great advantages in the survey and study of historical buildings from an operational point of view (safe, contactless, non-invasive, fast, resources), due to the usual complexity of spaces and the irregular forms of construction elements. In addition, the precision of the point clouds that can be obtained allows the detailed study of the topography of the constructions. Therefore, it opens the door to multiple investigations that will have an impact on conservation measures, restoration interventions, or even reconstructions. In addition, the quality and quantity of the data that it is possible to obtain allows the development of new methodological approaches to deepen and advance the knowledge of these constructions. 
In that sense, deformation assessments are essential in architectural heritage conservation. Many studies have developed simple (and not so simple) to address deformation of ancient structures from point clouds. Examples of it are the studies performed in the church of Santa Maria of Portonovo [15], the Cantalovo church [16], the Palazzo d'Accursio [17] (the three of them in Italy); the church of Santa Maria de Arties [18] or the Cathedral of Tortosa [19] (both in Spain), among many others. TLS surveys and displacement assessments can be also combined with other procedures of structural analysis [20], [21]. The aforementioned cases exemplify the complexity and variety of possible issues that can involve the deformation analysis in historical buildings. In that sense, it is interesting the study performed in [22] which deepens in modeling strategies of point clouds for deformation analysis.

Another issue that is becoming more and more prominent is the monitoring of ancient constructions. In these cases, the detection of deformations uses to involve successive surveys. This is the case for example of the displacements monitoring of railway bridges in Poland, where TLS surveys are combined with traditional measuring techniques [23], or the deformation monitoring of the Tower of Buddhist Incense in the Summer Palace (China) [24].

Other examples involve the deformations analysis of specific structural elements from point clouds, such as concrete arch structures [25,26] or irregular timber structures [27]. Most recent investigations have introduced the use of artificial intelligence to measure deformations in cultural heritage structures [28].

This article shows a methodological approach for the study of heritage architectural elements from the point of view of formal alterations. The objective is to systematize the analysis of the formal alterations through elementary processes, in order to identify the approaches that provide more relevant information on each construction element. The research starts from the assumption that a topographic reference base is often not available, and therefore a reflection on the reference forms to be used in an initial study is necessary. Thus, the time factor is not introduced through different epochs to surveys that allow a comparison to be established, but rather a single reading is used.

The investigation is based on a point cloud obtained with a TLS. Given the infinite possibilities offered by a point cloud for a formal study, a systematization of the work processes is proposed to obtain the information that is most relevant from a constructive point of view. For this, a corner of the cloister of the Cathedral of Tarragona has been used. It is highlighted in the ground floor of the cloister, which was obtained from a laser scanning survey made by the authors (Figure 1). The cathedral enclosure is one of the most relevant medieval buildings in Catalonia, and the structure of the cloister has relevant formal alterations that, even though they are very obvious, do not appear to have damaged the structure. Thus, the study focuses on identifying formal anomalies that may be related to movements of the structure or to deviations during construction.

The study assumes the great difficulty of differentiating between the anomalies that appeared during the construction process from those that have appeared later due to settlements of the construction elements or due to anthropogenic causes. Despite this, the information obtained allows a first approach to understanding the current state of the structure, establishing reference information for future controls. The research starts from an initial approximation from massive data capture techniques in which an analysis of the equilibrium conditions of the structure was also carried out [29]. This article deepens into the possibilities of formal analysis and notably expands the data initially provided. 


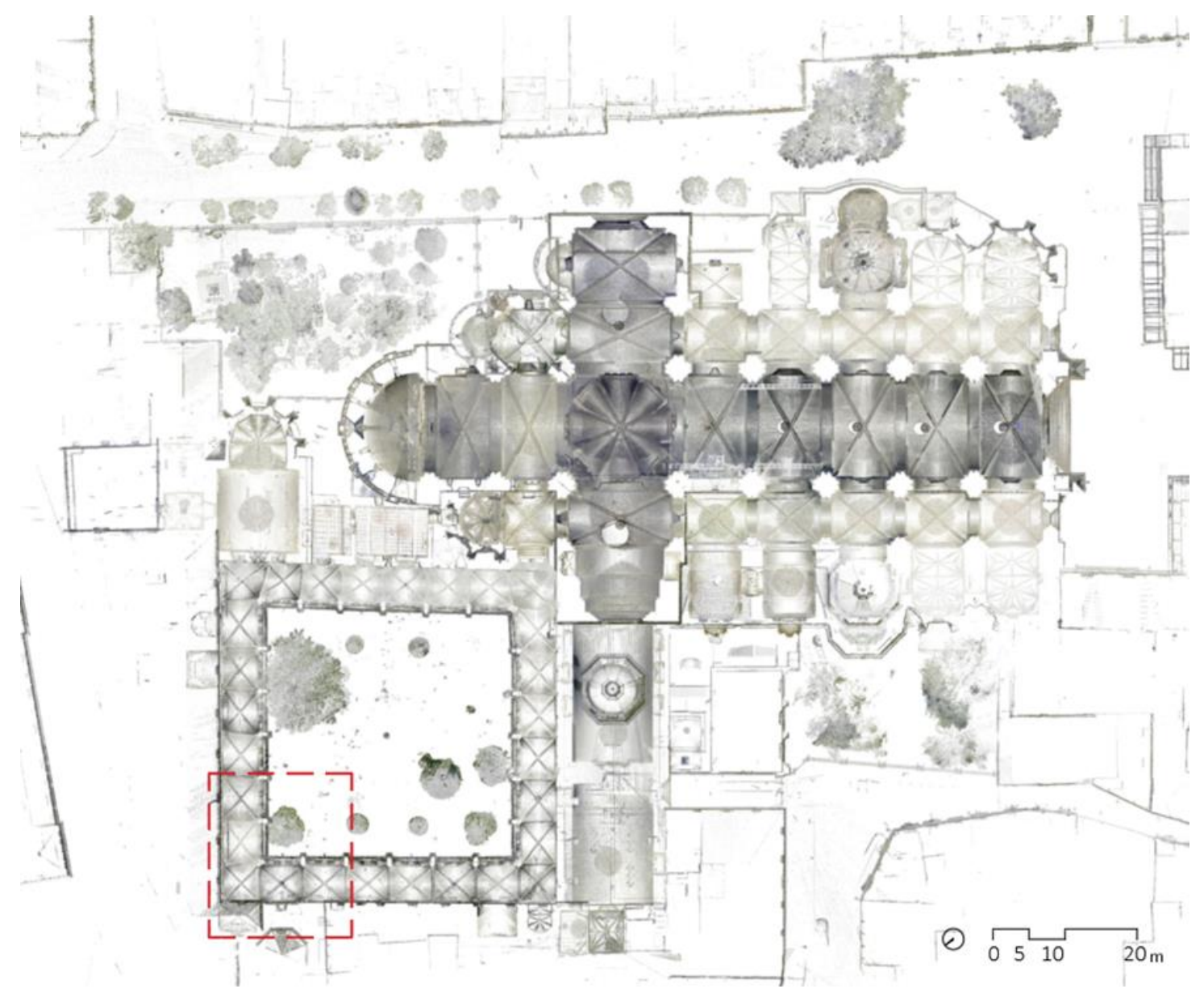

Figure 1. Ground floor of the Cathedral of Tarragona and the studied cloister corner.

\section{Materials and Methods}

\subsection{Case Study}

The Cathedral of Tarragona is one of the most emblematic buildings in the city, both for its architectural presence and for its historical and symbolic value. Located in the so called "part alta", presides the city as it rises to its highest position.

The construction began in the middle of the twelfth century. It was conceived as a big Romanesque building, but it presented clear Gothic elements when it was finished in the 14th century. Thus, it is one of the best examples of transition between the two architectural styles in Catalonia.

Historically, its construction led to the reinstatement of the Tarraconense diocese. It was the oldest diocese documented in the Iberian Peninsula, which disappeared after the Islamic conquest of 714. To emphasize that historical legitimacy, that has its origins in Roman times, the building was located in the same site where the temple dedicated to Emperor Augustus was built, in the ancient city of Tarraco.

The cloister (Figure 2) is a 12th century construction, although it was completed at the beginning of the 13th century. Its situation breaks the canonical scheme of contemporary cloisters since it is located in the upper left part of the transept. This is due to the use of pre-existing Roman structures, specifically the wall of the Temenos that delimited the sacred area of the temple of Augustus. This imposing wall stood more than $12 \mathrm{~m}$ in height, and more than 115 linear meters are still preserved in the city. This wall served as a boundary of the cloister, where the medieval perimeter wall adheres directly to the Roman wall. It is a singularity in the history of architecture and causes a variable of uncertainty in the mechanical behavior of this wall. 


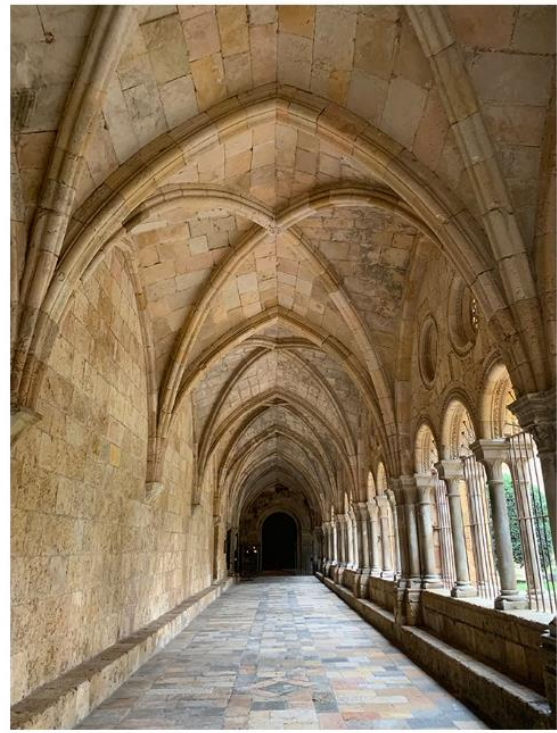

a)

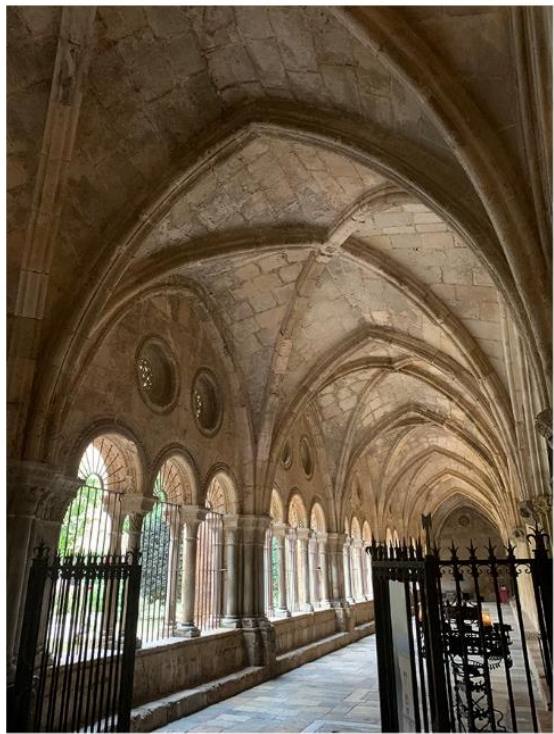

c)

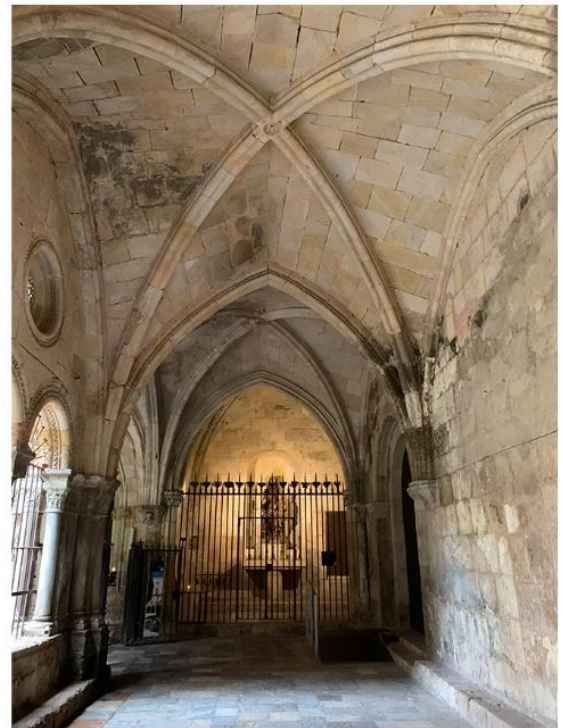

b)

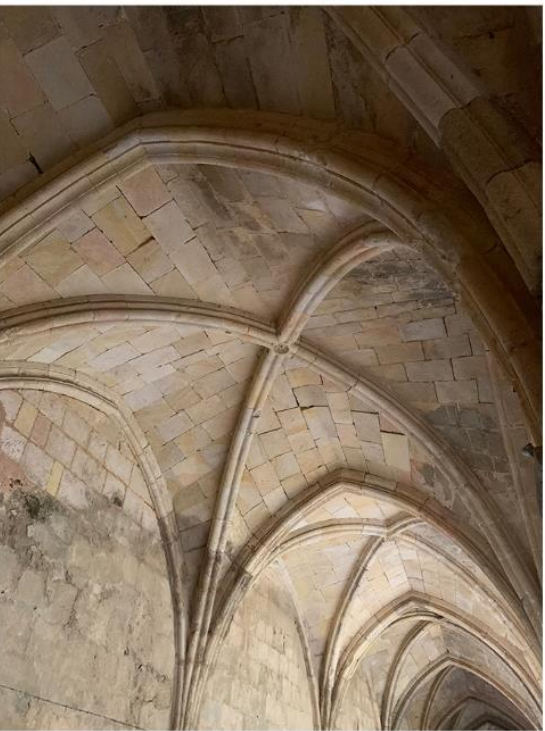

d)

Figure 2. View of the northern corner: (a) west gallery view, (b) north gallery view, (c) east gallery view from the corner, (d) close view of the vault V4.

The ground plan of the cloister defines a shape close to that of the square. The length of the four galleries measure $47.4 \mathrm{~m}$ (east gallery), $46.60 \mathrm{~m}$ (south gallery), 46.90 (west gallery), and $47.60 \mathrm{~m}$ (north gallery). Each gallery is divided in six structural bays with a ground plan of about $4 \times 5.5 \mathrm{~m}$, and there is another bay in each corner, so there is a total of 28 structural bays.

Bays are covered by a pointed ribbed cross vault, separated from each other by pointed transverse arches. The lower half part of the wall next to the garden is opened in each bay. The upper part is supported by three rounded arches over twin columns. The upper part is perforated by two circular lunettes.

The perimeter wall of the cloister is perforated in different areas. Thus, we can find four chapels built in different epochs after the construction of the cloister, together with nine doors that connect the cloister with the nave of the cathedral and other dependencies. 
The area studied in this article corresponds to the northwestern corner of the cloister, which is coincident with the angle of the wall of the Roman Temenos which was. The area studied involves five bays, four of which have rectangular ground plan, while the corner bay defines a square.

\subsection{Methodology}

The research is based on the survey carried out with a Leica RTC360 terrestrial laser scanner. A total of 32 positions were made, which covered the entire north-western corner of the cloister, generating a cloud of 8,020,570,206 points with an average density of 1 point every $0.75 \mathrm{~mm}$. The registration error was $0.002 \mathrm{~m}$, enough for the study to develop.

The analysis aims to systematize the methodology to identify and quantify formal anomalies, which are understood as those alterations in the shape of construction elements with respect to the predictable or regular shape. It is therefore necessary to discretize the different elements under study. Thus, we will distinguish between walls (vertical structure) and arches and vaults (horizontal closing structure). The analysis focuses on the interior walls of the gallery, and five bays have been selected.

The study of vertical and horizontal elements requires differentiated analysis processes. In general terms, these processes have to deal, on the one hand, with the difficulty of not having an original form of reference. On the other hand, with the different formal and dimensional characteristics of the elements. A nomenclature is established to determine each of the vaulted bays analyzed (Figure 3).

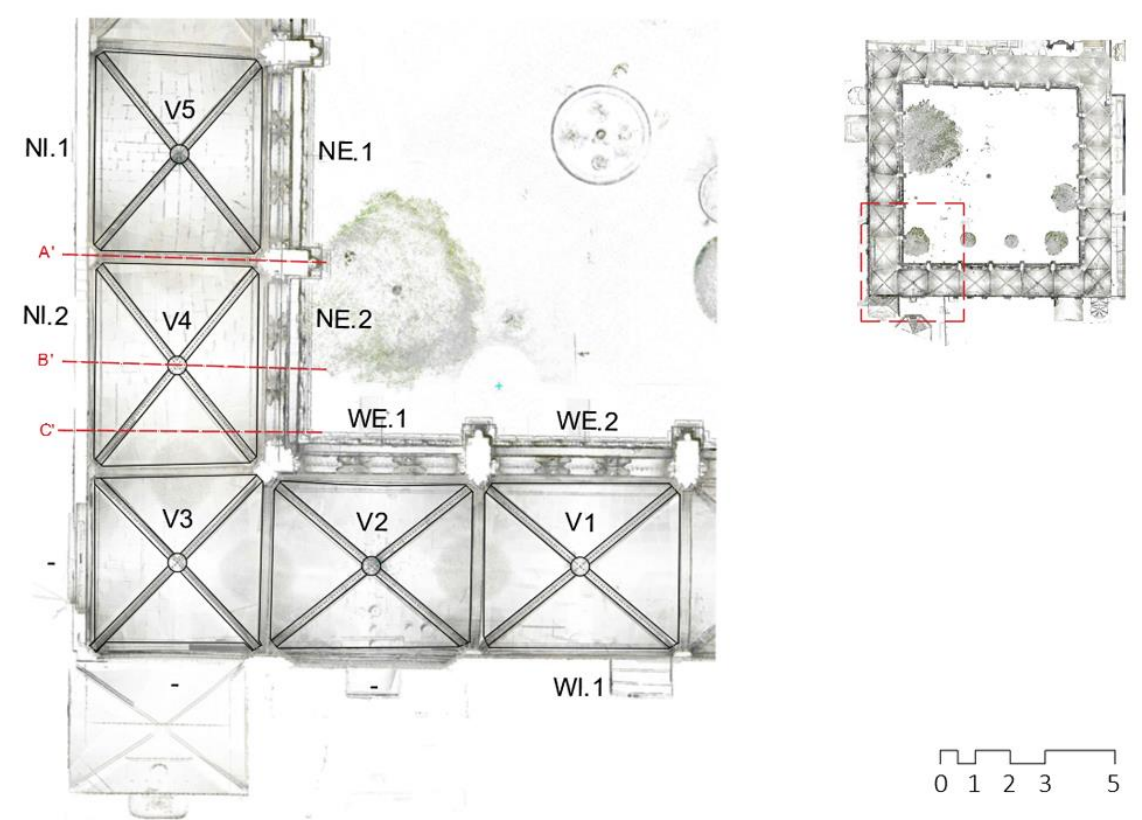

Figure 3. Nomenclature used for vaults and walls.

For the analysis of the vertical structure, different approaches are tested from the definition of a vertical comparison plane, using the software Cloud Compare. The visible faces from the interior of the gallery are analyzed, differentiating between the interior wall (I) and the exterior wall (E), and between the north side $(\mathrm{N})$ and the west side $(\mathrm{W})$.

On the west side (W) only one of the three bays of the inner wall is analyzed (WI.1), since the other two correspond to the chapel of the "Mare de Deu del Claustre" and do not have a wall. It must also be taken into account that the bay studied has an access door to the rear gallery that accesses the Roman wall in the other side. In total, the bay wall measures $6 \mathrm{~m}$ in length and $5.80 \mathrm{~m}$ in height.

On the north side, the corner bay has the access door to the space between the old Roman wall and the existing topography. This space is about $9 \mathrm{~m}$ wide and was used by different medieval structures. 
Thus, two bays of the north inner wall are analyzed (NI.1 and NI.2), with a total length of about $12 \mathrm{~m}$ long and $5.90 \mathrm{~m}$ in height. The two panels are calculated independently and also as a single wall.

The analysis process basically consists of defining a reference plane, and adjusting it to the point cloud considering three cases:

(a) Considering a free plane in relation to the point cloud, the plane that best approximates the point cloud centered on a point is calculated, together with the normal vector $(\mathrm{N})$ whose direction is expressed by its azimuth (units in sexagesimal degrees), and its inclination by its zenith angle.

(b) With the previous data and considering the plane as vertical. The origin point of the plane is moved if necessary, so that there is no systematic offset.

(c) Considering a set of points located between $5 \mathrm{~cm}$ and $35 \mathrm{~cm}$ high from the ground, the line that best approximates it is calculated and a vertical plane is defined. The origin point is moved to compensate for a possible systematic error, if necessary.

The planes defined with an average residual point-plane distance less than $1 \mathrm{~cm}$, are considered valid. All the adjustments were made using the RANSAC method, for which a maximum distance to the primitive of $2.5 \mathrm{~cm}$ from the points considered was used, with a resampling of $10 \mathrm{~cm}$, a maximum deviation from the normal of $15^{\circ}$, and a reliability of $99.9 \%$.

The inner walls of the gallery are continuous, while the exterior walls have openings: two oculi in the upper part, and a large opening divided into three parts by paired columns of circular section, which support the upper part of the wall by means of three rounded arches. Furthermore, the lower part is not located in the same plane as the upper part, but there is a setback of approximately $15 \mathrm{~cm}$.

The appropriate comparison planes are defined for the study of flatness for both the interior and exterior walls. Thus, in the section WI.1 of the west wall, the three approaches ((a), (b), and (c)) are tested. In the inner north wall, approaches ((a) and (b)) are used for sections (1, 2, and $1+2)$, and method (c) is used only for $(1+2)$, otherwise it would be redundant because the Sections 1 and 2 define a practically perfect straight in plan.

On the other hand, in the exterior walls, method (a) is used but not method (b), since the base is in a different plane than the upper part and would distort the results. The approximation (c) is used to define the plane according to the lower part, so that quantitatively, the results of the distances in the upper parts of the walls add up to the plane difference between the lower and upper section.

Complementary, a 2D verification is carried out in the north bay adjacent to the corner, and three cut planes $\left(\mathrm{A}^{\prime}, \mathrm{B}^{\prime}\right.$, and $\left.\mathrm{C}^{\prime}\right)$ are defined (Figure 3 ). That cross-section of the openings aims to visualize the medieval wall in relation to the Roman wall.

For the analysis of the vaults, two approaches are proposed using the program 3DReshaper. The first consists of obtaining a reference vault for each of the vaults, based on the edges that define their geometry. The second is based on the location of a common horizontal comparison plane, which will make it possible to relate the different vaults, defining an elevation map.

A 3D model is generated from the point cloud of the five bays of the cloister, obtaining a mesh of $31,568,273$ triangles and $703 \mathrm{~m}^{2}$ of surface, with an average size of triangles of $0.018 \mathrm{~cm}^{2}$. The vaults in particular were solved with 11,769,622 triangles, with an average size of $0.0012 \mathrm{~cm}^{2}$.

Once the mesh is obtained, the geometry of reference is defined for each vault through selected points. The imposts of the different arches (ribs, cross arches, and transverse arches) and the keystones, both of the vault and of the arches, are established. Finally, a third point is defined in the middle of each arch. The model is completed with the surface that covers the space between arches (Figure 4). Each theoretical vault is then compared with the equivalent real vault. This model assumes the deformations that the arches may have undergone over time, and allows the identification of anomalies mainly in the severies.

Regarding the elevation map, a height difference of $0.15 \mathrm{~m}$ has been identified on the ground floor. A horizontal comparison plane is defined at $5.00 \mathrm{~m}$ height from the average height of the ground 
(Figure 5). This position is above the spring line, which makes it possible to avoid the lower part of the vaults, which is very vertical compared to the rest of the surface.

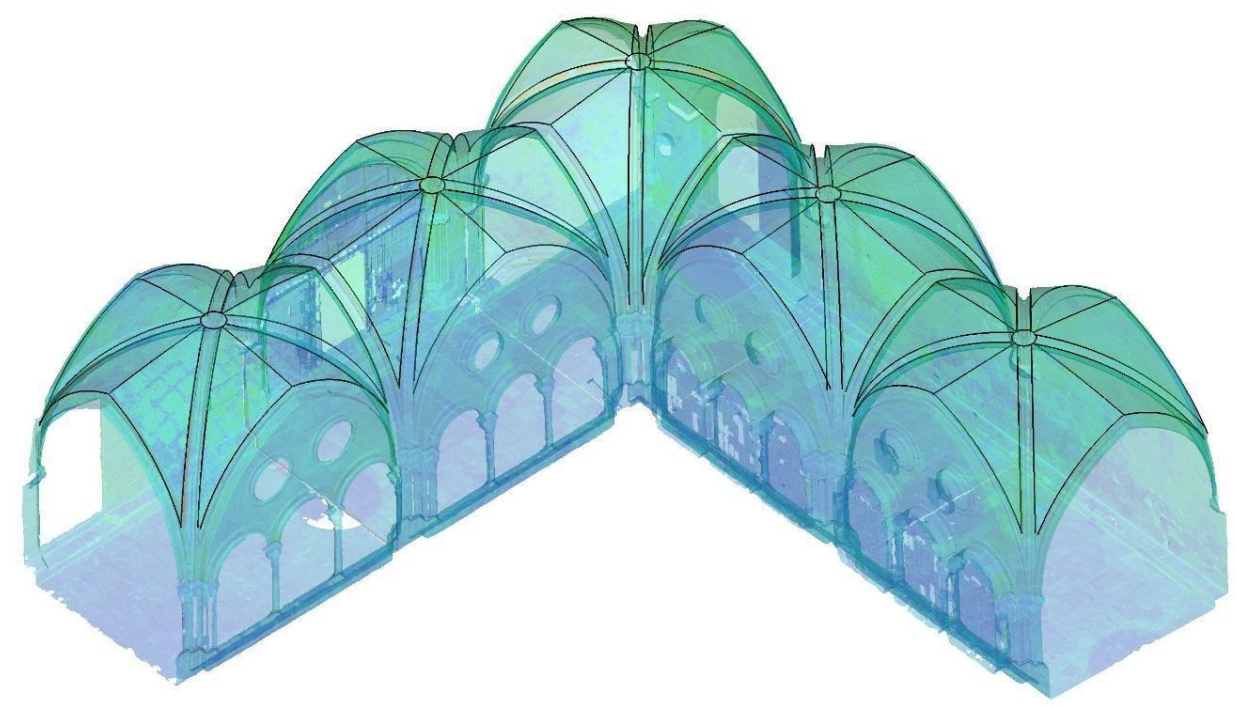

Figure 4. Mesh of the north corner of the cloister of the Cathedral of Tarragona.

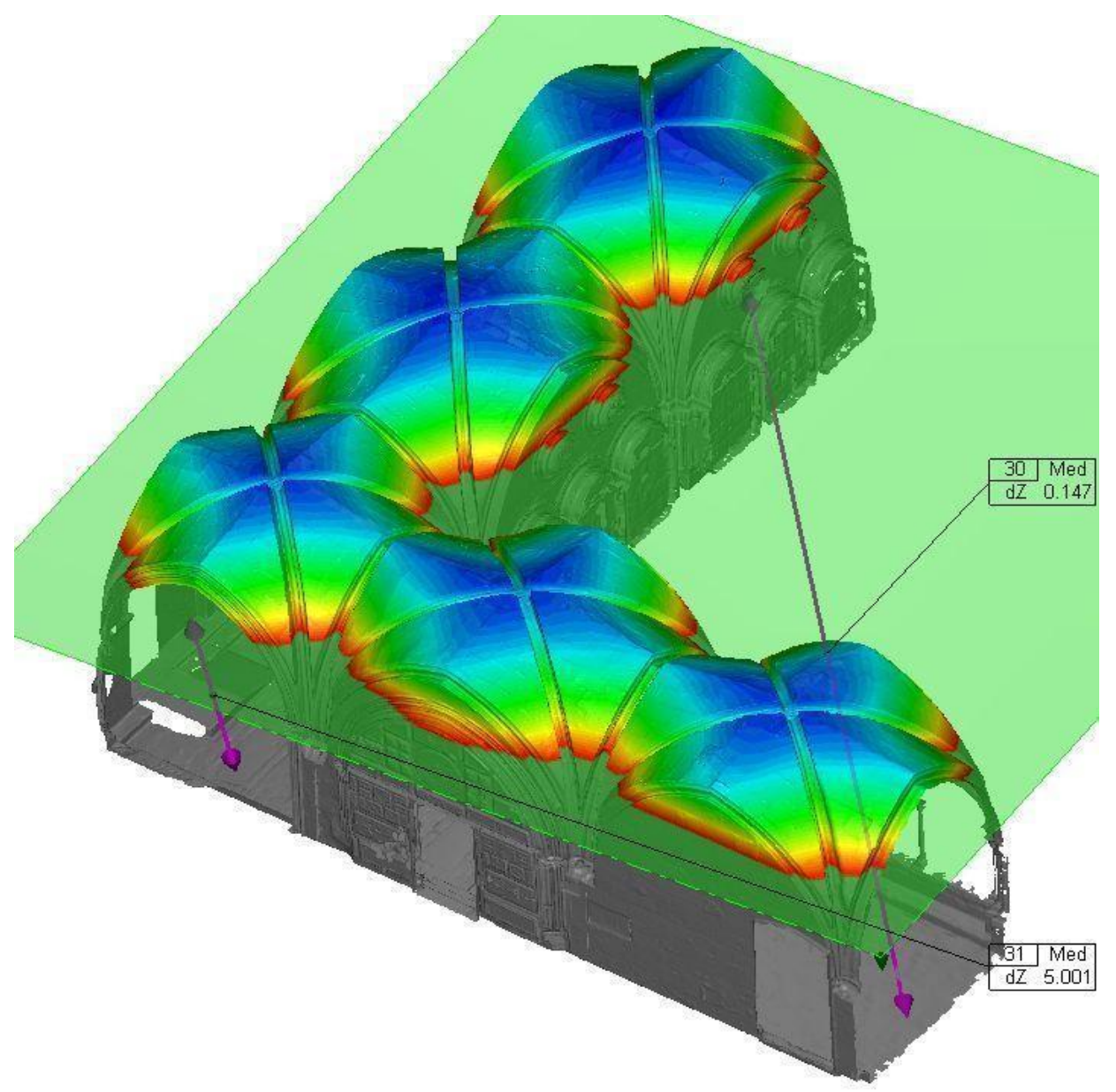

Figure 5. Horizontal reference planes (units in meters). 


\section{Results}

\subsection{Walls Assessment}

The cross sections have made it possible to verify the verticality of the walls, both on the side of the gallery and on the Roman wall (Figure 6). The total thickness measured in the cross section ( $\left.\mathrm{B}^{\prime}\right)$ is $1.036 \mathrm{~m}$, which includes the thickness of the Roman wall and the medieval addition. It is obvious that this information is very partial, and its function is to establish a control section. In addition, it allows us to intuit some anomalies. In the case of section $\left(\mathrm{B}^{\prime}\right)$, a certain bulging of the wall towards the interior is already sensed, for example.
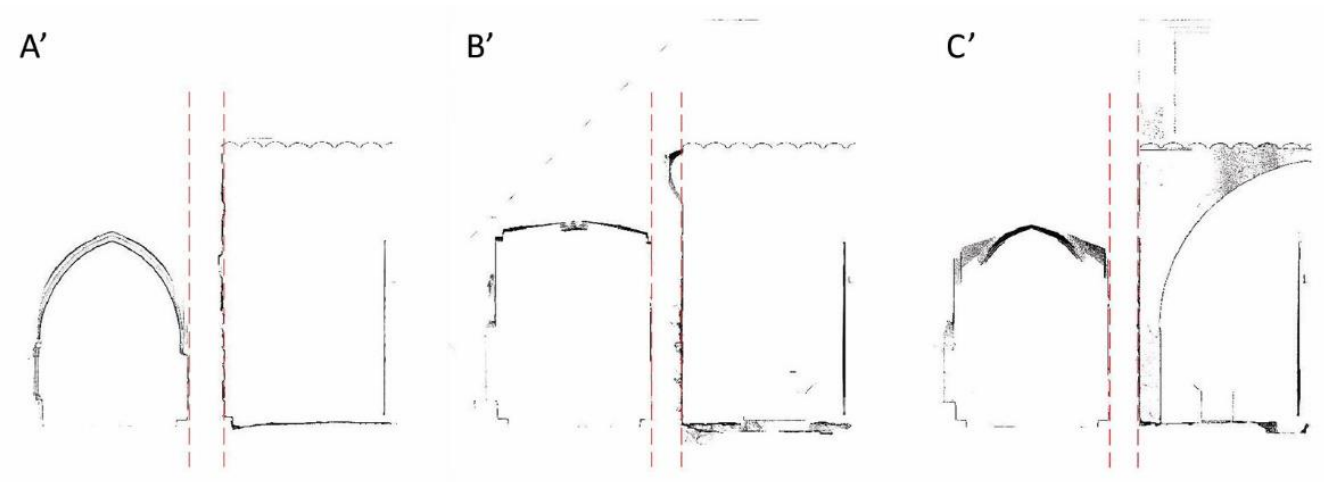

Figure 6. Cross sections of the cloister from the cut planes $\mathrm{A}^{\prime}, \mathrm{B}^{\prime}$ and $\mathrm{C}^{\prime}$.

The study of the verticality of the walls in three dimensions has made possible to detect more deviations. (Table 1) compiles the main parameters of the comparison planes obtained according to the different approximations proposed ((a), (b), and (c)). The results indicate small differences between the comparison planes obtained.

Table 1. Reference planes statistics of distance points-plane

\begin{tabular}{cccccccc}
\hline BAY & METH & $\begin{array}{c}\text { Average } \\
(\mathbf{m})\end{array}$ & $\begin{array}{c}\text { Std Dev } \\
(\mathbf{m})\end{array}$ & Min (m) & Max (m) & \% ( $\pm \mathbf{2 . 5}$ cm) & No. Pts \\
\hline WI.1 & (a) & 0.001 & 0.009 & -0.028 & 0.028 & 98.6 & $1,016,467$ \\
WI.1 & (b) & -0.003 & 0.015 & -0.050 & 0.045 & 93.5 & $1,016,467$ \\
WI.1 & (c) & -0.005 & 0.017 & -0.060 & 0.058 & 86.5 & $1,016,467$ \\
\hline NI.1 & (a) & -0.002 & 0.010 & -0.042 & 0.037 & 99.2 & $1,886,586$ \\
NI.1 & (b) & -0.006 & 0.013 & -0.050 & 0.035 & 94.0 & $1,886,586$ \\
NI.2 & (a) & 0.000 & 0.005 & -0.020 & 0.019 & 99.9 & $1,893,059$ \\
NI.2 & (b) & -0.002 & 0.007 & -0.025 & 0.020 & 94.7 & $1,893,059$ \\
NI1+2 & (a) & 0.005 & 0.017 & -0.047 & 0.042 & 86.4 & $3,779,645$ \\
NI1+2 & (b) & 0.004 & 0.017 & -0.054 & 0.055 & 83.3 & $3,779,645$ \\
NI1+2 & (c) & 0.006 & 0.017 & -0.048 & 0.043 & 84.2 & $3,779,645$ \\
\hline WE.1 & (c) & -0.079 & 0.061 & -0.270 & 0.126 & 23.2 & 863,707 \\
WE.1 & (a) & 0.003 & 0.009 & -0.040 & 0.029 & 98.8 & 276,866 \\
WE.2 & (c) & -0.109 & 0.068 & -0.215 & 0.038 & 26.1 & 374,081 \\
WE.2 & (a) & 0.006 & 0.008 & -0.034 & 0.031 & 99.3 & 134,708 \\
\hline SE.1 & (c) & -0.104 & 0.069 & -0.312 & 0.089 & 23.0 & 792,774 \\
SE.1 & (a) & 0.004 & 0.007 & -0.030 & 0.025 & 99.4 & 270,631 \\
SE.2 & (c) & -0.086 & 0.060 & -0.280 & 0.086 & 22.2 & 942,233 \\
SE.2 & (a) & 0.009 & 0.006 & -0.035 & 0.025 & 99.8 & 294,047 \\
\hline
\end{tabular}

Regarding the numerical results obtained from the comparison with the point cloud of the walls. (Table 2) synthesizes the main parameters obtained. From a quantitative point of view, the analysis of results focuses on the interior walls, since the change in plane between the lower and upper part of 
the exterior walls distorts the values in method (c). According to the average distance (mean) and the standard deviation (STD), it is observed how method (a) is the one that best approximates the real wall, and method (c) the one that raises the greatest discrepancies. In turn, the latter is the one that allows us to identify the leaning suffered by the walls. The maximum out of plumb values according to method (c) are found at SI. $1=0.058 \mathrm{~m}$ and WI. $1+2=0.055 \mathrm{~m}$. It is also striking how when considering sections $1+2$ on the north wall, the values tend to equalize (Figure 7 ).

Table 2. Comparison between reference planes and the walls point cloud

\begin{tabular}{|c|c|c|c|c|c|c|c|}
\hline BAY & METH & $\begin{array}{c}\text { Average } \\
\text { (m) }\end{array}$ & $\begin{array}{c}\text { Std Dev } \\
(\mathrm{m})\end{array}$ & $\operatorname{Min}(\mathrm{m})$ & $\operatorname{Max}(\mathrm{m})$ & $\%( \pm 2.5 \mathrm{~cm})$ & No. Pts \\
\hline WI.1 & (a) & 0.001 & 0.009 & -0.028 & 0.028 & 98.6 & $1,016,467$ \\
\hline WI.1 & (b) & -0.003 & 0.015 & -0.050 & 0.045 & 93.5 & $1,016,467$ \\
\hline WI.1 & (c) & -0.005 & 0.017 & -0.060 & 0.058 & 86.5 & $1,016,467$ \\
\hline $\min$ & & -0.005 & 0.009 & -0.060 & 0.028 & & \\
\hline $\max$ & & 0.001 & 0.017 & -0.028 & 0.058 & & \\
\hline diff & & -0.006 & 0.008 & 0.032 & 0.030 & & \\
\hline NI.1 & (a) & -0.002 & 0.010 & -0.042 & 0.037 & 99.2 & $1,886,586$ \\
\hline NI.1 & (b) & -0.006 & 0.013 & -0.050 & 0.035 & 94.0 & $1,886,586$ \\
\hline NI.2 & (a) & 0.000 & 0.005 & -0.020 & 0.019 & 99.9 & $1,893,059$ \\
\hline NI.2 & (b) & -0.002 & 0.007 & -0.025 & 0.020 & 94.7 & $1,893,059$ \\
\hline $\mathrm{NI} 1+2$ & (a) & 0.005 & 0.017 & -0.047 & 0.042 & 86.4 & $3,779,645$ \\
\hline $\mathrm{NI} 1+2$ & (b) & 0.004 & 0.017 & -0.054 & 0.055 & 83.3 & $3,779,645$ \\
\hline $\mathrm{NI} 1+2$ & (c) & 0.006 & 0.017 & -0.048 & 0.043 & 84.2 & $3,779,645$ \\
\hline $\min$ & & -0.006 & 0.005 & -0.054 & 0.019 & & \\
\hline $\max$ & & 0.006 & 0.017 & -0.020 & 0.055 & & \\
\hline diff & & -0.012 & 0.012 & 0.034 & 0.036 & & \\
\hline WE.1 & (c) & -0.079 & 0.061 & -0.270 & 0.126 & 23.2 & 863,707 \\
\hline WE.1 & (a) & 0.003 & 0.009 & -0.040 & 0.029 & 98.8 & 276,866 \\
\hline WE.2 & (c) & -0.109 & 0.068 & -0.215 & 0.038 & 26.1 & 374,081 \\
\hline WE. 2 & (a) & 0.006 & 0.008 & -0.034 & 0.031 & 99.3 & 134,708 \\
\hline $\min$ & & -0.109 & 0.008 & -0.270 & 0.029 & & \\
\hline $\max$ & & 0.006 & 0.068 & -0.034 & 0.126 & & \\
\hline diff & & -0.115 & 0.060 & 0.236 & 0.097 & & \\
\hline NE.1 & (c) & -0.104 & 0.069 & -0.312 & 0.089 & 23.0 & 792,774 \\
\hline NE.1 & (a) & 0.004 & 0.007 & -0.030 & 0.025 & 99.4 & 270,631 \\
\hline NE. 2 & (c) & -0.086 & 0.060 & -0.280 & 0.086 & 22.2 & 942,233 \\
\hline NE. 2 & (a) & 0.009 & 0.006 & -0.035 & 0.025 & 99.8 & 294,047 \\
\hline $\min$ & & -0.104 & 0.006 & -0.312 & 0.025 & & \\
\hline $\max$ & & 0.009 & 0.069 & -0.030 & 0.089 & & \\
\hline diff & & -0.113 & 0.063 & 0.282 & 0.064 & & \\
\hline
\end{tabular}

From a qualitative point of view, the comparison plane defined according to method (a) makes it possible to identify the anomalies in terms of the flatness of the wall, as well as to identify the inclination of the wall, expressed as the zenith inclination of the reference plane. On the other hand, methods (b) and (c) are two approximations to establish the leaning from the reference plane. The case of (b) has the limitation that the plane does not coincide with the wall in the base, so it is not possible to quantify the leaning of the wall, data that is obtained by method (c). Thus, the differences between both approaches are tested on the interior wall, while on the exterior wall, approach (b) is not used. 

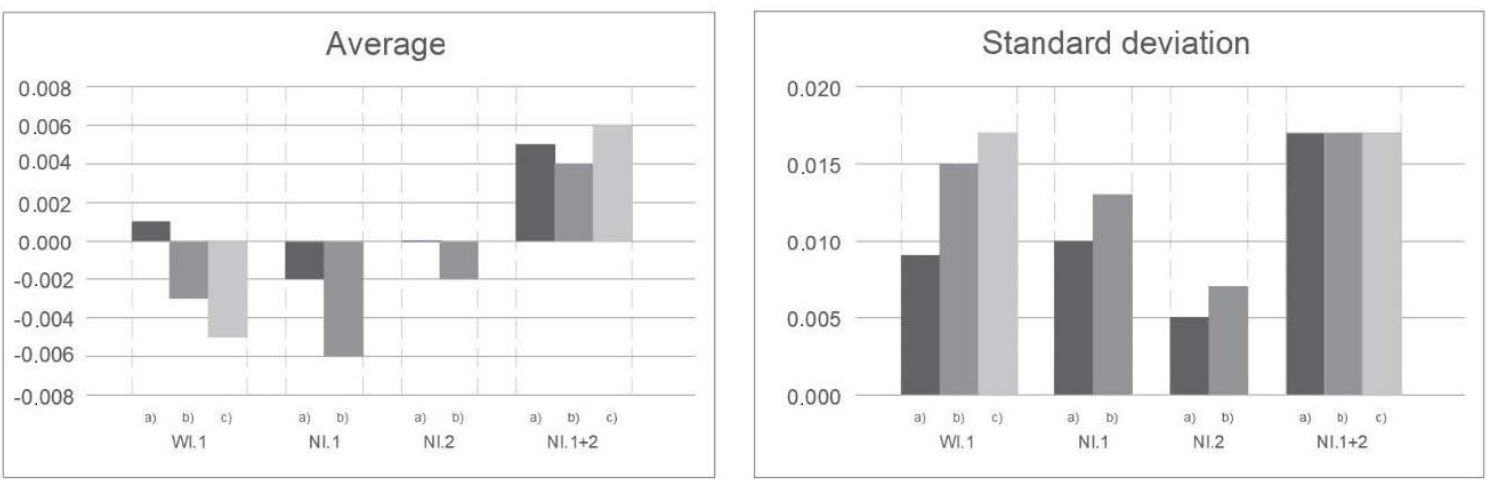

Figure 7. Statistical analysis of distances between reference planes and the walls point cloud. Units in meters.

The distance maps corroborate the values indicated in (Table 2), and allow identifying the areas where the main discrepancies occur. In the case of the west interior wall (SI.1), the definition of the comparison plane (a) establishes smaller distances than (b) and (c). In any case, the main distances are in the upper part of the wall, with a leaning towards the interior of the gallery (Figure 8).

WEST WALL

A) INCLINED PLANE METHOD
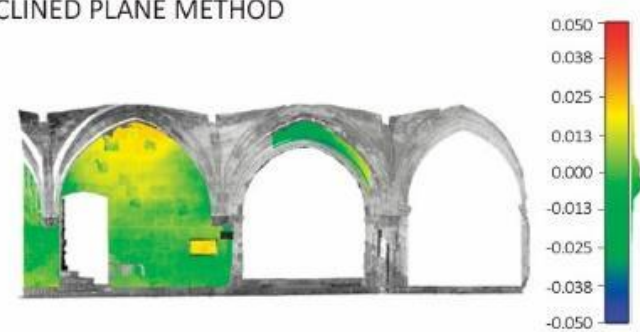

B) VERTICAL PLANE METHOD

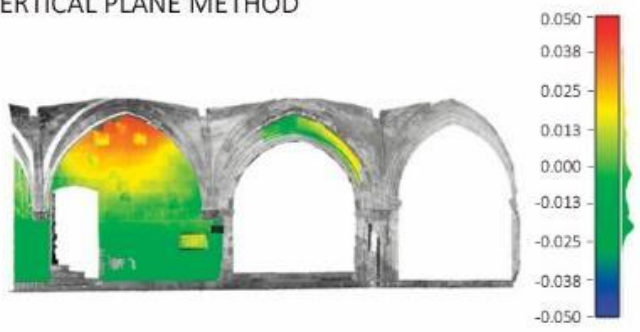

C) VERTICAL PLANE METHOD ( $5 \mathrm{~cm}$ bar)
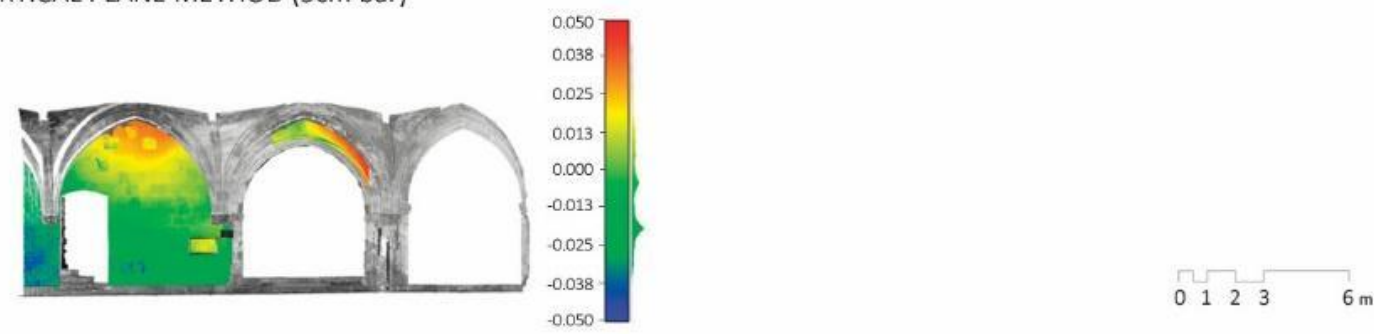

Figure 8. Distance maps of inner west wall (units in meters).

On the north wall, the different areas where the main discrepancies are concentrated according to the reference plane stand out. Thus, in section NI.1 the highest values are concentrated in the central part of the wall, while in section NI.2 they are concentrated in the upper part. In both cases, the anomaly occurs towards the interior of the gallery. The results change when the plane is defined from the two bays $(1+2)$. Thus, for the three methods $((a),(b)$, and $(c))$ in section NI.1, the highest values are concentrated in the center and upper left, while in NI.2 they are found on the right side (Figure 9).

On the other hand, the results are shown on the exterior walls according to method (c). It is observed how the sections NE.1 and NE.2 concentrate the anomalies on the side near the corner, with NE.2 being the one with the highest values. In the west section, section WE.1 is very well plumbed, while section WE. 2 is the one that presents a clearer out of plumb, although this occurs in the arches supported by the paired columns. It can be interpreted that, in this case, there is a leaning of the upper part of the wall towards the center of the cloister (Figure 10). 


\section{NORTH WALL}

\section{NI.1}

\section{A) INCLINED PLANE METHOD}

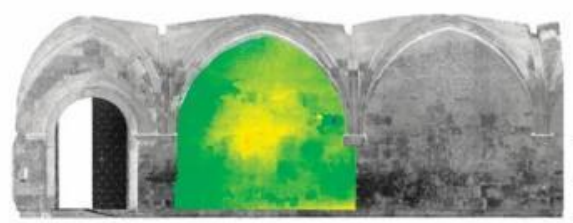

NI.2

A) INCLINED PLANE METHOD

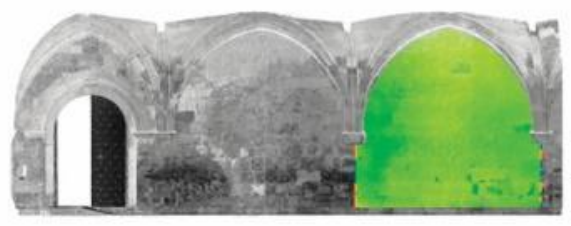

NI. $1+2$

A) INCLINED PLANE METHOD

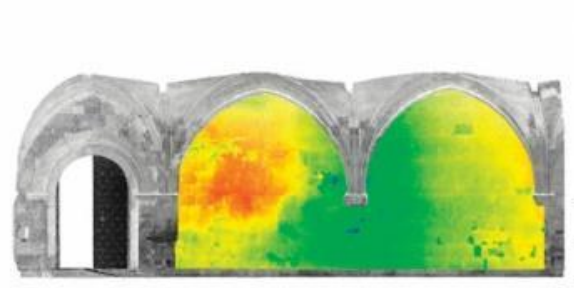

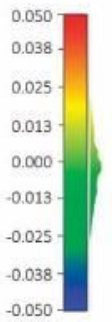
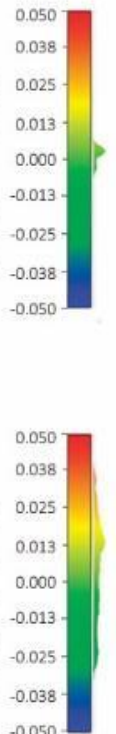

B) VERTICAL PLANE METHOD

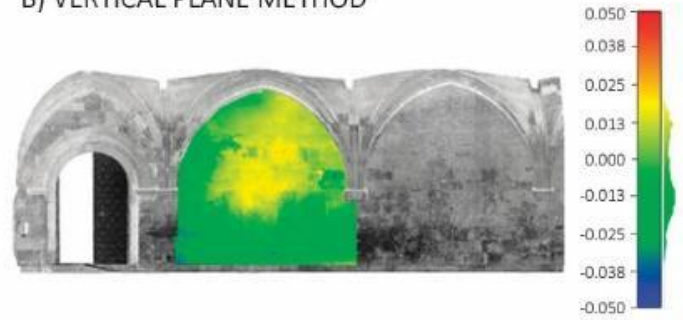

B) VERTICAL PLANE METHOD

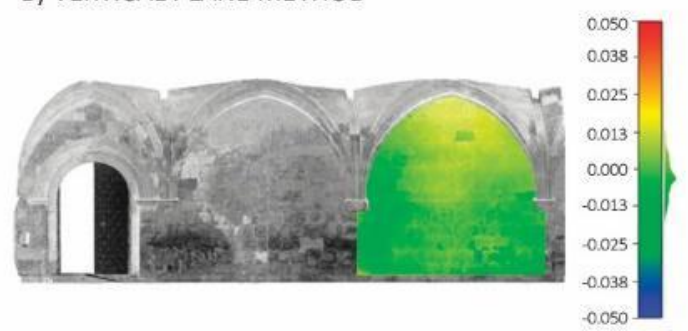

B) VERTICAL PLANE METHOD

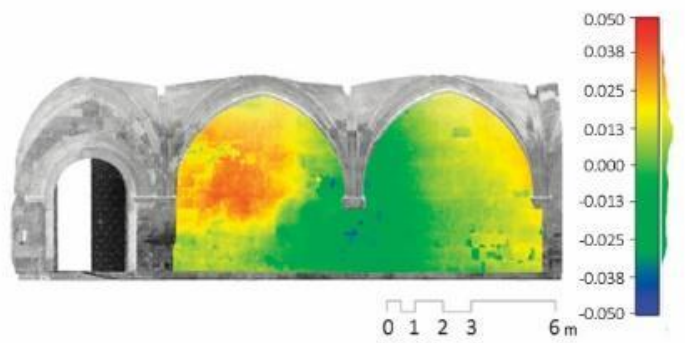

Figure 9. Distance maps of inner north wall (units in meters).

\subsection{Vaults Assessment}

The results are expressed in the form of a map of distances between each vault and the equivalent modeled vault. The nerves have not been modeled so the analysis has focused on the anomalies of the severies. For this reason, the map of the nerves appears in red (Figure 11). The histogram that accompanies the figure is common to all the vaults, so it is representative of the whole and not of each individual vault. Quantitatively, the high coincidence between the reference model and the construction can be verified. The range of distances $(0.004-0.045 \mathrm{~m})$ is the most representative involving $37.8 \%$ of the points, followed by the range $(0.045-0.094 \mathrm{~m})$ with a percentage of $26.5 \%$ of the points.

From a qualitative point of view, the analysis reveals that each one of them presents a particular distance pattern, and no discrepancies or common patterns are identified in different vaults.

If we take the data in (Figure 12) as a reference, the closer vaults to the reference vault are V3 and V5, with $54.90 \%$ and $55.00 \%$ of the points correspondingly, which are coincident.

Regarding the study of the vaults in relation to a common horizontal reference plane, the distance map shows the formal differences between theoretically equal vaults. These differences go beyond those caused by differences in the ground floor measures, since in each individual vault there are anomalies that distort the symmetry that should exist in their deployment. Vault V4 is especially remarkable, since the longitudinal vertex is evidently misaligned to the sides of the vault keystone. 
NE.1

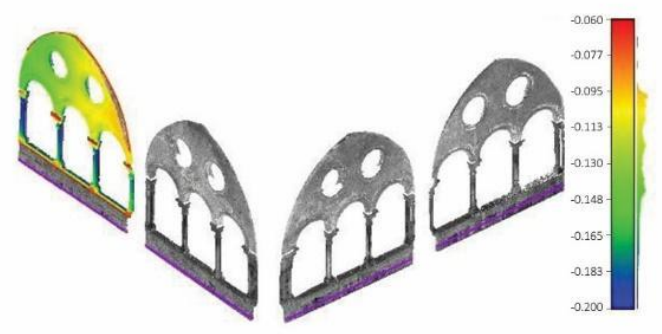

WE.1

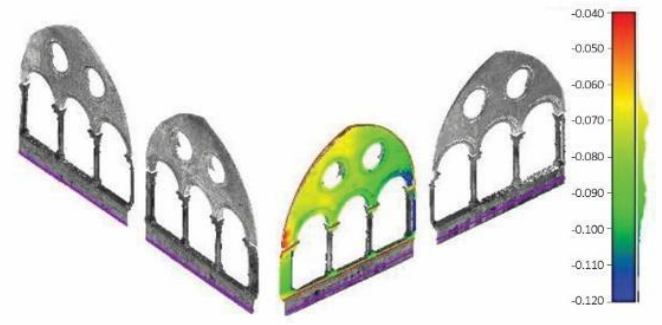

NE. 2

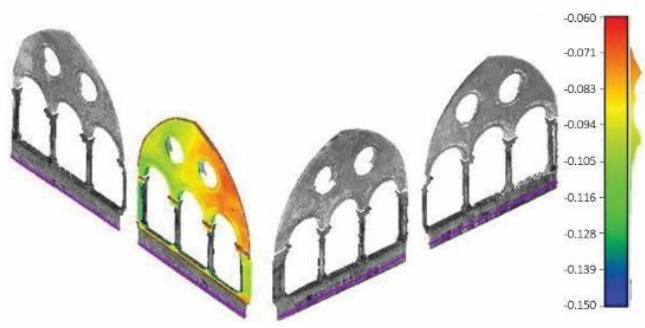

WE. 2

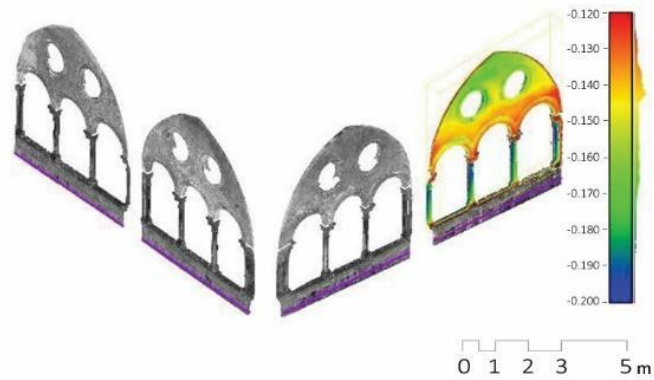

Figure 10. Distance maps of external walls (units in meters).
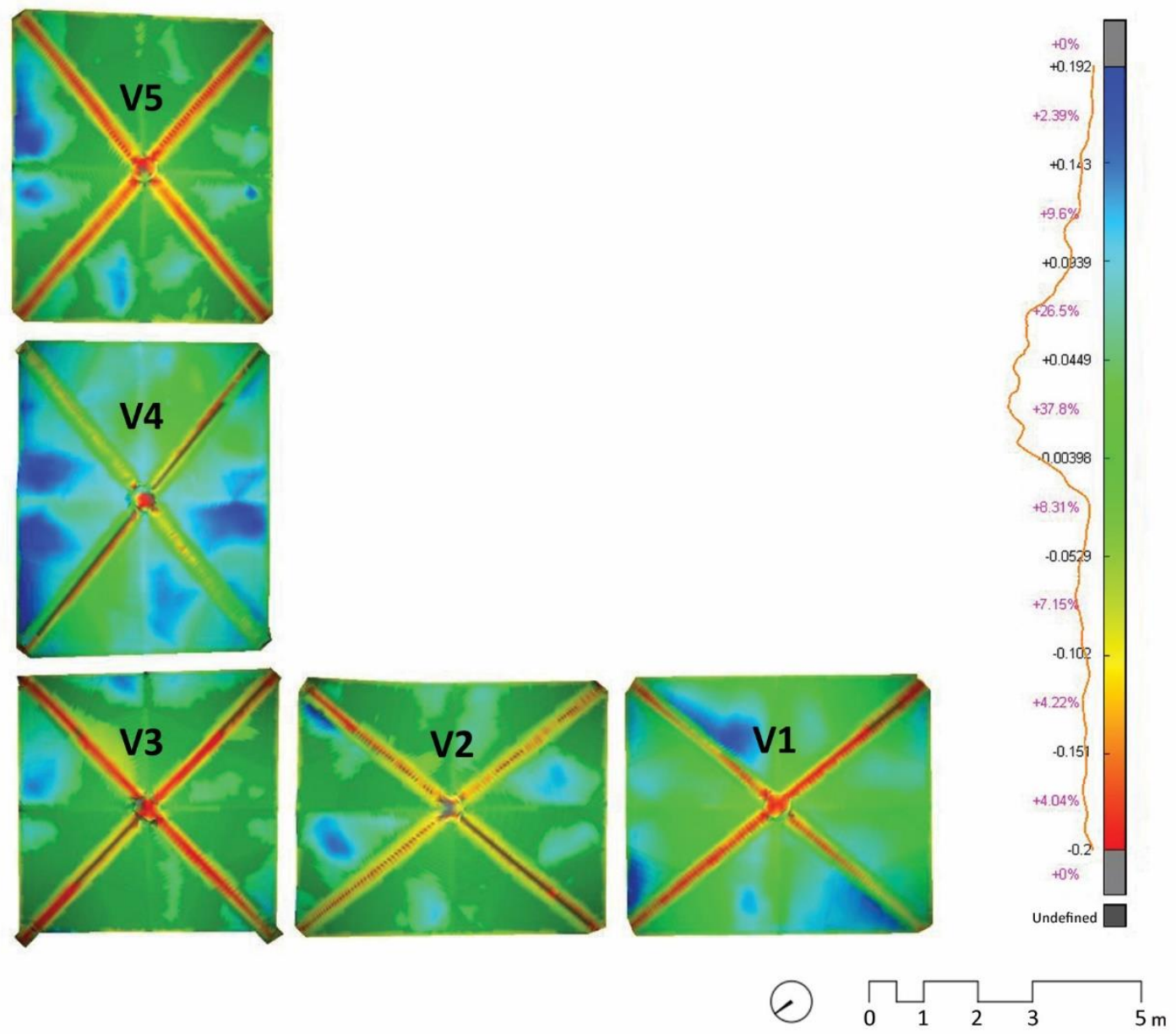

Figure 11. Distance maps between reference vaults and point clouds (units in meters). 


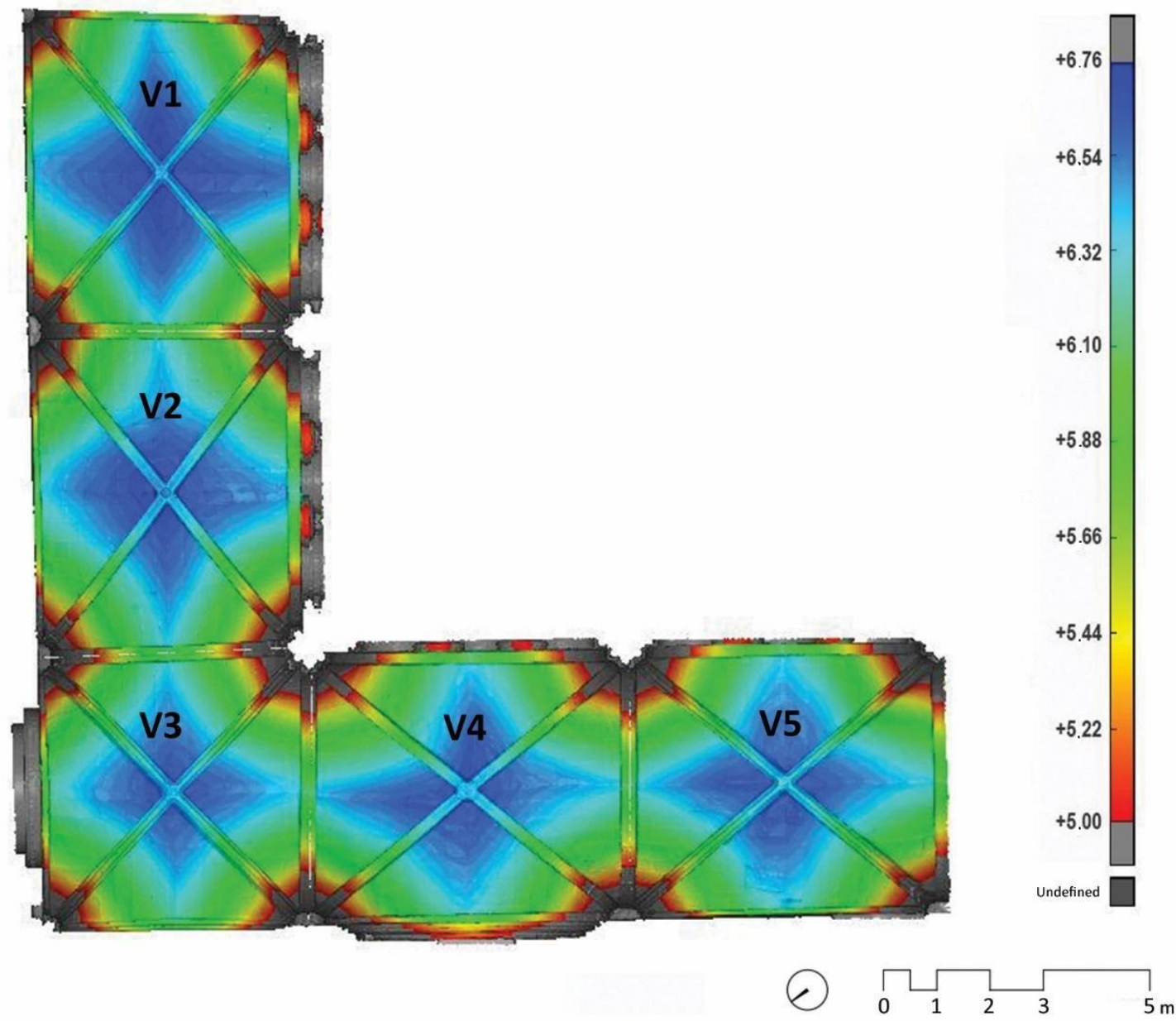

Figure 12. Distance maps between reference horizontal plane and point clouds (units in meters).

\section{Discussion}

The study has tested a methodological systematization for the analysis of formal anomalies in masonry structures based on reference forms in the case study of the Tarragona Cathedral cloister. The detection of these anomalies is a fundamental issue in diagnosis, which must lead to the definition of conservation measures and intervention if necessary. It is clear that there is no novelty in the methods themselves. The research focuses on the differences obtained through the tested approaches and their influence in the evaluation of the construction. This kind of analysis can be carried out with great precision and ease thanks to the topographical basis obtained by the use of remote sensing techniques, such as TLS. It allows us to obtain a continuous point cloud with homogeneous quality as a whole.

In addition, the results obtained have shown the need to adapt the method to the construction elements. The study of verticality of walls from comparison planes starts from a very simple approach, but even in walls with small deformations such as those analyzed, the differences in the definition of the comparison plane involve relevant changes in the results, both quantitatively and qualitatively.

It is remarkable the limitations of the approach in the study of the exterior wall, due to the elements that compose it. The non-alignment of the bottom part with respect to the top makes it difficult to have a reliable measurement from method (c). On the other hand, the paired columns, which have a fundamental role as a hinge in the balance of the structure, have not been analyzed, due to their shape and location. Future research will have to systematically address the study of these elements.

Moreover, the Roman wall of the Temenos has not suffered appreciable variations in its verticality, despite it being more than $12 \mathrm{~m}$ high and that it was designed to support only its own weight. Several 
structures have been added over the wall through the centuries, which do not appear to have affected the integrity of the masonry.

Regarding the vaults, the study has revealed the formal anomalies in the severies regarding a reference form obtained from the current ribs and arches. This approach incorporates the possible deformations that the masonry has suffered over the centuries. An alternative would be to approach the theoretical layout of the vaults to establish an undeformed reference shape. In any case, to be able to propose the systematic study of all the vaults of the cloister, it would be convenient to incorporate some semi-automated system, since each vault starts from a different ground plan layout, and it would be necessary to model them individually.

The analysis of vaults from the comparison plane allows us to obtain an easy and intuitive document to detect formal anomalies from the visual comparison between theoretically equal vaults. Some of the anomalies detected could be related to settlements of both the support system and/or the vaults themselves. Another option would be that deviations appeared during construction, be it due to errors in setting out or execution of the falsework or the masonry itself.

In any case, there it seems to be no relation between the anomalies of walls and vaults. Anyway, the case analysis is a small part of the cloister, and it is very difficult to draw conclusions about the possible movements suffered, and the state of conservation as a whole. Further research will deepen in the systematization of the identification of formal anomalies, with the aim of studying the entire cloister. This will allow us to obtain new conclusions in several issues: the possible relation between movements, the global behavior of the structure related to the anomalies identified, and the effect of the coexistence with the Roman wall, which makes it a unique case study. In this sense, the mechanical analysis of the interaction between the different elements will also be of great interest for future research.

Author Contributions: Conceptualization, F.B., M.A.N.-A., A.C.-J. and J.M.P.; Funding acquisition, F.B. and J.M.P.; Investigation, F.B., M.A.N.-A., A.C.-J., D.M. and J.M.P.; Methodology, F.B., M.A.N.-A., A.C.-J., D.M. and J.M.P.; Software, F.B., D.M. and J.M.P.; Supervision, M.A.N.-A., A.C.-J. and J.M.M.; Visualization, D.M.; Writing-review and editing, F.B., M.A.N.-A., A.C.-J., J.M.P. and J.M.M. All authors have read and agreed to the published version of the manuscript.

Funding: This research received no external funding.

Acknowledgments: The author A.C.-J. is a Serra Hunter fellow.

Conflicts of Interest: The authors declare no conflict of interest.

\section{References}

1. Xie, W.; He, Q.; Zhang, K.; Guo, L.; Wang, X.; Shen, J.; Cui, Z. Application of terrestrial laser scanner on tidal flat morphology at a typhoon event timescale. Geomorphology 2017, 292, 47-58. [CrossRef]

2. Massiot, C.; Nicol, A.; Townend, J.; McNamara, D.; Garcia-Sellés, D.; Conway, C.E.; Archibald, G. Quantitative geometric description of fracture systems in an andesite lava flow using terrestrial laser scanner data. J. Volcanol. Geotherm. Res. 2017, 341, 315-331. [CrossRef]

3. Abbas, M.A.; Lichti, D.D.; Chong, A.K.; Setan, H.; Majid, Z.; Lau, C.L.; Idris, K.M.; Ariff, M.F.M.; Luh, L.C. Improvements to the accuracy of prototype ship models measurement method using terrestrial laser scanner. Measurement 2017, 100, 301-310. [CrossRef]

4. Suchocki, C.; Katzer, J. An example of harnessing Terrestrial Laser Scanner for remote sensing of saturation of chosen building materials. Constr. Build. Mater. 2016, 122, 400-405. [CrossRef]

5. Pavlidis, G.; Koutsoudis, A.; Arnaoutoglou, F.; Tsioukas, V.; Chamzas, C. Methods for 3D digitization of Cultural Heritage. J. Cult. Herit. 2007, 8, 93-98. [CrossRef]

6. England, H. 3D Laser Scanning for Heritage: Advice and Guidance on the Use of Laser Scanning in Archaeology and Architecture; Historic England: Swindon, UK, 2018. 
7. Monego, M.; Fabris, M.; Menin, A.; Achilli, V. 3-D SURVEY APPLIED TO INDUSTRIAL ARCHAEOLOGY BY TLS METHODOLOGY. Int. Arch. Photogramm. Remote Sens. Spat. Inf. Sci. 2017, 42, 449-455. [CrossRef]

8. Martínez, S.; Ortiz, J.; Gil-Docampo, M.; Rego, M.T. Recording Complex Structures Using Close Range Photogrammetry: The Cathedral of Santiago De Compostela. Photogramm. Rec. 2013, 28, 375-395. [CrossRef]

9. Sapirstein, P. Accurate measurement with photogrammetry at large sites. J. Archaeol. Sci. 2016, 66, 137-145. [CrossRef]

10. Fassi, F.; Achille, C.; Fregonese, L. Surveying and modelling the main spire of Milan Cathedral using multiple data sources. Photogramm. Rec. 2011, 26, 462-487. [CrossRef]

11. Monego, M.; Previato, C.; Bernardi, L.; Menin, A.; Achilli, V. Investigating Pompeii: Application of 3D geomatic techniques for the study of the Sarno Baths. J. Archaeol. Sci. Rep. 2019, 24, 445-462. [CrossRef]

12. Grussenmeyer, P.; Landes, T.; Voegtle, T.; Ringle, K. Comparison methods of terrestrial laser scanning, photogrammetry and tacheometry data for recording of cultural heritage buildings. Int. Arch. Photogramm. Remote Sens. Spat. Inf. Sci. 2008, 37, 213-218.

13. Pandžić, J.; Pejić, M.; Božić, B.; Erić, V. Error model of direct georeferencing procedure of terrestrial laser scanning. Autom. Constr. 2017, 78, 13-23. [CrossRef]

14. Koutsoudis, A.; Vidmar, B.; Ioannakis, G.; Arnaoutoglou, F.; Pavlidis, G.; Chamzas, C. Multi-image 3D reconstruction data evaluation. J. Cult. Herit. 2014, 15, 73-79. [CrossRef]

15. Quagliarini, E.; Clini, P.; Ripanti, M. Fast, low cost and safe methodology for the assessment of the state of conservation of historical buildings from 3D laser scanning: The case study of Santa Maria in Portonovo (Italy). J. Cult. Herit. 2017, 24, 175-183. [CrossRef]

16. Bonali, E.; Pesci, A.; Casula, G.; Boschi, E. Deformation of Ancient Buildings inferred by Terrestrial Laser Scanning methodology: The Cantalovo church case study (Northern Italy). Archaeometry 2013, 56, 703-716. [CrossRef]

17. Pesci, A.; Bonali, E.; Galli, C.; Boschi, E. Laser scanning and digital imaging for the investigation of an ancient building: Palazzo d'Accursio study case (Bologna, Italy). J. Cult. Herit. 2012, 13, 215-220. [CrossRef]

18. De Catalunya, U.I.; Coll-Pla, S.; Costa-Jover, A.; Piquer, M.L.; I Virgili, U.R. Evaluation of large deformations on Romanesque masonry pillars: The case of Santa María de Arties (XII-XIII) at Valle de Arán, Spain. Rev. Constr. 2017, 16, 468-478. [CrossRef]

19. Jover, A.C.; Ginovart, J.L.; Coll-Pla, S.; Piquer, M.L. Using the terrestrial laser scanner and simple methodologies for geometrically assessing complex masonry vaults. J. Cult. Herit. 2019, 36, 247-254. [CrossRef]

20. Korumaz, M.; Betti, M.; Conti, A.; Tucci, G.; Bartoli, G.; Bonora, V.; Korumaz, A.G.; Fiorini, L. An integrated Terrestrial Laser Scanner (TLS), Deviation Analysis (DA) and Finite Element (FE) approach for health assessment of historical structures. A minaret case study. Eng. Struct. 2017, 153, 224-238. [CrossRef]

21. Almac, U.; Pekmezci, I.P.; Ahunbay, M.G. Numerical Analysis of Historic Structural Elements Using 3D Point Cloud Data. Open Constr. Build. Technol. J. 2016, 10, 233-245. [CrossRef]

22. Neuner, H.; Holst, C.; Kuhlmann, H. Overview on current modelling strategies of point clouds for deformation analysis. AVN 2016, 123, 328-339.

23. Gawronek, P.; Makuch, M.; Mitka, B.; Gargula, T. Measurements of the Vertical Displacements of a Railway Bridge Using TLS Technology in the Context of the Upgrade of the Polish Railway Transport. Sensors 2019, 19, 4275. [CrossRef] [PubMed]

24. Wei, Z.; Huadong, G.; Qi, L.; Tianhua, H. Fine Deformation Monitoring of Ancient Building Based on Terrestrial Laser Scanning Technologies. IOP Conf. Ser. Earth Env. Sci. 2014, 17, 12166. [CrossRef]

25. Yang, H.; Omidalizarandi, M.; Xu, X.; Neumann, I. Terrestrial laser scanning technology for deformation monitoring and surface modeling of arch structures. Compos. Struct. 2017, 169, 173-179. [CrossRef]

26. Yang, H.; Xu, X.; Neumann, I. Deformation behavior analysis of composite structures under monotonic loads based on terrestrial laser scanning technology. Compos. Struct. 2018, 183, 594-599. [CrossRef]

27. Cabaleiro, M.; Hermida, J.; Riveiro, B.; Caamaño, J. Automated processing of dense points clouds to automatically determine deformations in highly irregular timber structures. Constr. Build. Mater. 2017, 146, 393-402. [CrossRef] 
28. Wojtkowska, M.; Kedzierski, M.; Delis, P. Validation of terrestrial laser scanning and artificial intelligence for measuring deformations of cultural heritage structures. Measurement 2021, 167, 108291. [CrossRef]

29. Núñez-Andrés, M.A.; Buill, F.; Costa-Jover, A.; Puche, J.M. Structural assessment of the Roman wall and vaults of the cloister of Tarragona Cathedral. J. Build. Eng. 2017, 13, 77-86. [CrossRef]

Publisher's Note: MDPI stays neutral with regard to jurisdictional claims in published maps and institutional affiliations.

(C) 2020 by the authors. Licensee MDPI, Basel, Switzerland. This article is an open access article distributed under the terms and conditions of the Creative Commons Attribution (CC BY) license (http://creativecommons.org/licenses/by/4.0/). 